\title{
Endoscopic Sphinterotomy in Patients with Mild Acute Biliary Pancreatitis, in Situ Gallbladder and Alithiasic Bile Duct: Is It Justified?
}

\author{
Mario Anselmi Méndez¹, Ana María Gemmato Pascazio', Julio Salgado Oyarzún¹, \\ Maritza Flores Opazo²
}

${ }^{1}$ General and Digestive Surgery Department, School of Medicine, University of Concepción, Concepcion, Chile ${ }^{2}$ Public Health Department, School of Medicine, University of Concepción, Concepcion, Chile

Email: manselmi@udec.cl

How to cite this paper: Méndez, M.A., Pascazio, A.M.G., Oyarzún, J.S. and Opazo, M.F. (2021) Endoscopic Sphinterotomy in Patients with Mild Acute Biliary Pancreatitis, in Situ Gallbladder and Alithiasic Bile Duct: Is It Justified? Open Journal of Gastroenterology, 11, 118-133.

https://doi.org/10.4236/ojgas.2021.117013

Received: April 15, 2021

Accepted: July 23, 2021

Published: July 26, 2021

Copyright $\odot 2021$ by author(s) and Scientific Research Publishing Inc. This work is licensed under the Creative Commons Attribution International License (CC BY 4.0).

http://creativecommons.org/licenses/by/4.0/

\begin{abstract}
Objective: To compare the long-term results of the treatment of mild acute biliary pancreatitis in patients with gallbladder in situ, without stones in the bile duct, treated by cholecystectomy, and endoscopic sphincterotomy (ES) versus simple cholecystectomy in the prevention of recurrence of this pathology. Material and Methods: Between May 2008 and December 2012, 110 consecutive patients with a mild acute biliary pancreatitis (ABP) were prospectively studied. None had undergone cholecystectomy, and choledocholithiasis was ruled out by ERCP. Two groups of patients were created and randomized: Group I $(\mathrm{n}=55)$ who underwent ERCP plus ES and Group II $(\mathrm{n}=$ 55) only had diagnostic ERCP. Patients were then referred for cholecystectomy. Follow up was completed in 101 patients. Group I was made up of 53 patients and Group II had 48 similar characteristics. Patients were followed for an average of 105 months. At the end of the follow-up, 12 (22.6\%) from Group I and $6(12.5 \%)$ from Group II ( $\mathrm{p}=0.143$ ) remained with the gallbladder in situ. Results: There were 53 patients in Group I (100\%). Only $42(87.5 \%)$ of those in Group II evolved without biliopancreatic complications $(\mathrm{p}=0.0096)$. In the latter, $6(12.5 \%)$ were complicated, and 5 had not had cholecystectomy. In Group I patients, there was no recurrence of acute biliary pancreatitis, but this was seen in 4 cases $(8.4 \%)$ in Group II ( $\mathrm{p}=$ 0.0476). Group I also had 2 cases of biliary colic (4.2\%) and 2 cases of obstructive jaundice (4.2\%). Conclusions: The risk of recurrence is significant in patients with mild acute biliary pancreatitis, without bile duct stones, and in whom cholecystectomy is not performed; thus, an ES is recommended.
\end{abstract}




\section{Keywords}

Pancreatitis, Endoscopic Sphincterotomy

\section{Introduction}

The transit of one or more stones from the common bile duct to the duodenum through the papilla of Vater seems to be the initial event in the development of a ABP [1]. One of the main risk factors for this pathology is having the gallbladder in situ [2]. When it is not removed, a recurrence between $75 \%$ and $90 \%$ is recorded unless the patient is protected via a previous endoscopic sphincterotomy (ES) [3] [4] [5] [6] [7].

To avoid recurrence, the current recommendation for patients with mild disease is to perform cholecystectomy during the initial hospitalization [8] [9]. Most recent guidelines tend to recommend early cholecystectomy either during hospital admission or within 2 weeks of discharge [10] [11].

However, several studies have indicated that adherence to these guidelines in daily practice is as low as 5\% [12] [13] [14] [15]. A delay in cholecystectomy after mild acute biliary pancreatitis has been shown to be associated with a substantial risk of recurrent biliary events. If ES is performed during initial admission, then there could be reduced risk of recurrent pancreatitis, but this does not lessen the possibility of other biliary complications [13].

Some have suggested that the risk of recurrence of acute biliary pancreatitis is similar to that of the general population after cholecystectomy [16]. Others describe recurrence rates of $13 \%$ to $17 \%$. Such relapses have been attributed to bile duct lithiasis [17] [18].

Small stones can go unnoticed on ERCP or magnetic resonance imaging (MRCP) and even endoscopic ultrasound (EUS). In addition, in patients in whom the presence of choledocholithiasis has been ruled out preoperatively, stones between 3 and $5 \mathrm{~mm}$ are highly likely to migrate from the gallbladder to the bile duct between examination and cholecystectomy or during surgical manipulation of the gallbladder during its resection [19] [20] [21] [22] [23].

Because the vast majority of patients with acute biliary pancreatitis have a benign course disease, which is not altered by ERCP and endoscopic sphincterotomy, some studies suggest a more selective use such as in patients considered unfit for surgery or those with severe symptoms [24] [25] [26]. In patients with mild acute biliary pancreatitis and without bile duct stones, an ES can be performed and considered prophylactic treatment to prevent recurrent biliary events [7]. Non-randomized studies evaluating the effect of cholecystectomy and additional ES in patients with pancreatitis show contradictory results [27].

The potential advantages of ES are to improve the course of the disease by providing early decompression of the pancreaticobiliary system, removing retained stones from the common bile duct, or preventing recurrent episodes [7].

A 2016 study recommended that patients should undergo a cholecystectomy 
plus ERCP to prevent the recurrence of acute biliary pancreatitis [28]. Moreover, a recent large-scale study using data from more than 5000 patients showed that cholecystectomy and ES offer the best long-term outcome for preventing recurrent biliary pancreatitis [29].

Recent guidelines from the American Gastroenterological Association (AGA) recommend cholecystectomy during initial admission but not after discharge in patients with acute biliary pancreatitis (strong recommendation, moderate-quality evidence). They also warn against the routine use of urgent ERCP in patients with acute biliary pancreatitis and without cholangitis [10]. Importantly, this statement was considered a conditional recommendation based on low-quality evidence.

In a 2019 retrospective study, however, a lower incidence of recurrence of the pancreatic event was shown in patients with non-severe conditions who underwent non-urgent ERCP with ES compared to those who did not have ERCP regardless of the cholecystectomy plan. [30]. Our results suggest that ERCP with empirical ES is safe and reduces the risk of recurrent acute biliary pancreatitis in patients with non-severe disease. However, ES may not be adequate to prevent other gallstone-related complications [30].

Unfortunately, there are no prospective randomized clinical trials comparing the long-term results of ES plus cholecystectomy with only gallbladder resection [7] [31]. The aim of this study is to prospectively and randomly compare the long-term results of conservative treatment (cholecystectomy only) versus early endoscopic sphincterotomy followed by cholecystectomy in the recurrence of acute pancreatic symptoms in patients with mild acute biliary pancreatitis, gallbladder in situ, and without stones in the bile duct.

\section{Material and Method}

Between 05.01.08 and 12.31.12, a comparative, prospective, longitudinal, and randomized clinical study was performed that included a consecutive series of 110 patients with a diagnosis of mild acute biliary pancreatitis and gallbladder in situ who were admitted to the Teaching Unit of Endoscopic Surgery of the Department of Surgery of the Faculty of Medicine of the University of Concepción, Chile. Ranson's prognostic signs were used to predict the severity of pancreatitis [32]. Pancreatitis was considered mild if the patient had 3 or fewer prognostic signs.

\subsection{Inclusion Criteria}

- Upper abdominal pain

- Amylase or lipase levels at least 3 times above normal values

- Bilirubin $<5 \mathrm{mg} / \mathrm{dl}$

- Age over 18 years

- No alterations in coagulation

- Absence of pregnancy

- Gallbladder in situ

- Bile duct without stones on abdominal ultrasound 
- No evidence of alcoholic or metabolic origin as a cause of pancreatitis

\subsection{Exclusion Criteria}

- Acute pancreatitis of any other cause (alcoholic, metabolic, drugs, poisons, etc.)

- Absence of previous benign biliopancreatic pathology (chronic pancreatitis, sclerosing cholangitis, etc.)

- Absence of biliopancreatic neoplasia

- Absence of previous biliopancreatic surgery (surgical or endoscopic)

- Pregnancy

- Alteration of coagulation tests that contraindicate the procedure

Once the indication for the procedure was confirmed, the patient proceeded to sign the informed consent to be submitted according to the work protocol of that time of our Endoscopic Surgery Unit to an ERCP and eventual endoscopic sphincterotomy.

The study protocol was approved by the Ethics Committee of the Faculty and Ethical Standards for Research in Humans as specified in the Declaration of Helsinki [33]. All authors had access to the study data and reviewed and approved the final manuscript.

The vast majority of the procedures were performed under topical pharyngeal anaesthesia (4\% lidocaine spray) and under intravenous conscious sedation with Midazolam and Meperidine with doses scaled by age and condition of the patient. In the remaining cases, the examination was carried out with anaesthetic support using Propofol. In the presence of marked peristalsis, butyl-scopolamine bromide was administered as an antispasmodic in doses of 20 to $40 \mathrm{mg}$ i.v. During ERCP, the patients were monitored using a multi-parameter vital signs monitor. All procedures were performed by experienced endoscopists.

The equipment used were Olympus TJF 145 and 150, 160 VF, and Q180 V (Tokio Japan) duodenoscopes; these instruments were made by the same manufacturer (KD-211Q-1520 and/or KD-11Q-1).

Neither MRI nor USE was used to verify the absence of bile duct stones during the preoperative period. Surgeons at our hospital rarely performed intraoperative cholangiography. Therefore, ERCP was the best method at that time from both a diagnostic and therapeutic perspective for the management of biliopancreatic lithiasis.

Endoscopic cholangiography was ruled out via the presence of choledocholithiasis, and the cases were randomized by randomly opening a sealed envelope and specifying whether or not the patient would undergo an endoscopic sphincterotomy.

In this way, two groups of 55 patients were formed: One underwent a section of the sphincter of Oddi (Group I) and the other had a diagnostic endoscopic cholangiography leaving the ampulla intact (Group II). The techniques used were previously described [34].

ERCP was successful in all cases although some patients required more than 
one attempt (Group I: average 1.1 and Group II: average 1.02); only one patient from Group II had a pre-cut to achieve selective cannulation of the bile duct.

In Group I, one patient (1.8\%) evolved with mild post-ERCP pancreatitis. This patient was discharged after 48 hours. In group II, severe acute pancreatitis occurred in one patient $(1.8 \%)$ who had to be admitted to the ICU where she remained for 15 days. She recovered and was subsequently discharged in good condition. The patients were then returned to the referring surgeon for gallbladder excision.

Of the 110 initial patients, $9(8.2 \%)$ were lost to follow-up leaving 101 completed cases $(91.8 \%)$, which were considered for the statistical analysis. Group I had 53 patients and Group II had 48 cases. The mean follow-up was 105 months (Range 84 to 132 ).

The clinical characteristics of both groups excluding those lost to follow-up were similar (Table 1).

Table 1. Patient characteristics.

\begin{tabular}{|c|c|c|c|c|c|}
\hline & \multicolumn{2}{|c|}{ GROUP I } & \multicolumn{2}{|c|}{ GROUP II } & \\
\hline & $\mathrm{n}$ & $\%$ & $\mathrm{n}$ & $\%$ & \\
\hline Patients & 53 & & 48 & & $\mathrm{p}$-value \\
\hline \multicolumn{6}{|l|}{ Sex } \\
\hline Male & 13 & 24.5 & 9 & 18.8 & $0.4823^{*}$ \\
\hline Female & 40 & 75.5 & 39 & 81.3 & \\
\hline \multicolumn{6}{|l|}{ Age (years) } \\
\hline Average \pm SD & 39.817 .3 & & 36.413 .1 & & $0.448^{\star *}$ \\
\hline \multicolumn{6}{|l|}{ Echotomography } \\
\hline Cholelithiasis & 30 & 56.6 & 30 & 62,5 & $0.6823^{*}$ \\
\hline Acute lithiasic cholecystitis & 18 & 34.0 & 14 & 29.2 & \\
\hline Biliary sludge & 3 & 5.7 & 2 & 4.2 & \\
\hline Alithiasic gallbladder & 2 & 3.8 & 2 & 4.2 & \\
\hline \multicolumn{6}{|l|}{ Bile duct diameter (mm) } \\
\hline Average \pm SD & $6.9 \pm 2.2$ & & $7.2 \pm 2.4$ & & $0.299^{* *}$ \\
\hline \multicolumn{6}{|l|}{ Jaundice } \\
\hline Yes & 24 & 45.3 & 29 & 60.4 & $0.1283^{*}$ \\
\hline No & 29 & 54.7 & 19 & 39.6 & \\
\hline \multicolumn{6}{|l|}{ Duodenum conditions } \\
\hline Normal & 46 & 86.8 & 43 & 89.6 & $0.4811^{*}$ \\
\hline Peripapillar diverticulum & 5 & 9.4 & 3 & 6.3 & \\
\hline Edematous & 2 & 3.8 & 1 & 2.1 & \\
\hline \multicolumn{6}{|l|}{ Papilla conditions } \\
\hline Normal & 29 & 54.7 & 25 & 52.1 & $0.969^{*}$ \\
\hline Dilated ostium & 24 & 45.3 & 23 & 47.9 & \\
\hline \multicolumn{6}{|l|}{ Bile duct cannulation } \\
\hline First attempt successful & 47 & 88.7 & 47 & 97.9 & $0.07569^{*}$ \\
\hline Second attempt successful & 6 & 11.3 & 1 & 2.1 & \\
\hline
\end{tabular}

${ }^{\star}$ Chi squared; ${ }^{* *}$ Student $\mathrm{t}$ Test. 


\subsection{Statistical Analysis}

The Chi squared test was used to analyze qualitative data, and Fisher's exact test was chosen when the number of observations was small. Student's $t$ test was used for numerical data. A p-value $<0.05$ was considered significant.

\section{Results}

At the end of the follow-up, 18 patients (17.8\%) remained with the gallbladder in situ (Table 2).

The 53 patients in Group I with or without gallbladder in situ evolved without biliopancreatic complications, but only $42 / 48(87.5 \%)$ were seen in those in Group II $(\mathrm{p}=0.0096)$. In the latter, morbidity was found in $6(12.5 \%)$ with 8 complications. One of these patients corresponded to a case previously undergoing cholecystectomy and the other 5 still had gallbladder in situ. The morbidity rate of the group of patients without ES was significantly higher than patients with a section of the sphincter of Oddi (Table 3).

When comparing the evolution of the groups according to the presentation of biliary complications, the patients who underwent an ES did not develop this type of morbidity, but it appeared in $8.3 \%$ of those without sphincterotomy. This difference was not statistically significant (Table 4).

One case with biliary colic pain (patient still without cholecystectomy) had undergone ERCP without sphincterotomy and requested hospital discharge the day after the endoscopic procedure. Considering the previous admission diagnosis, the patient underwent a new ERCP 6 days later during which the gallbladder was contrasted showing filling defects compatible with stones, an alithiasic $7 \mathrm{~mm}$ bile duct, and a dilated cystic duct. This time, an endoscopic sphincterotomy was added to ERCP, and the patient evolved without complications. The cholecystectomy

Table 2. Cholecystectomy at the end of follow-up.

\begin{tabular}{cccccc}
\hline & \multicolumn{6}{c}{ GROUP I } & \multicolumn{2}{c}{ GROUP II } \\
\hline & $\mathbf{n}$ & $\%$ & $\mathbf{n}$ & $\%$ & $\mathbf{p}$ \\
\hline Cholecistectomy & & & & & \\
Yes & 41 & 77.4 & 42 & 87.5 & $0.143^{*}$ \\
No & 12 & 22.6 & 6 & 12.5 & \\
\hline
\end{tabular}

${ }^{*}$ Chi squared.

Table 3. Biliopancreatic morbidity at the end of follow-up.

\begin{tabular}{cccccc}
\hline & \multicolumn{2}{c}{ GROUP I } & \multicolumn{2}{c}{ GROUP II } & \\
\hline Morbidity & $\mathrm{n}$ & $\%$ & $\mathrm{n}$ & $\%$ & $\mathrm{p}$ \\
\hline Biliary & 0 & 0 & 4 & 8.3 & \\
Acute pancreatitis & 0 & 0 & 4 & 8.3 & \\
Total & 0 & 0 & 8 & 16.6 & $0.00195^{\star}$ \\
\hline
\end{tabular}

${ }^{\star}$ Chi squared. 
Table 4. Complications according to type of treatment.

\begin{tabular}{ccccccc}
\hline & \multicolumn{2}{c}{ GROUP I } & \multicolumn{2}{c}{ GROUP II } & \\
\hline & $\mathrm{n}=53$ & $\%$ & $\mathrm{n}=48$ & $\%$ & p-value \\
\hline Biliary colic with gallbladder in situ & 0 & 0 & 1 & 2.1 & \\
Post cholecystectomy biliary colic & 0 & 0 & 1 & 2,1 & \\
Post-cholecystectomy obstructive jaundice & 0 & 0 & 1 & 2.1 & \\
Obstructive jaundice with gallbladder in situ & 0 & 0 & 1 & 2.1 & \\
TOTAL & 0 & 0 & 4 & 8.4 & 0.2036 \\
\hline
\end{tabular}

${ }^{* * *}$ Chi-squared Test.

was carried out 6 days after ERCP. The surgery was successful, and the patient progressed satisfactorily being asymptomatic at the end of the follow-up.

The other patient presented colicky pain had ERCP without sphincterotomy on 08.25.09 and laparoscopic cholecystectomy 6 days later. He remained asymptomatic for 4 years after the pain, and he evolved with obstructive jaundice as verified by the clinic and laboratory. He underwent ERCP, and the bile duct was contrasted. This was seen to be dilated but alithiasic. An endoscopic sphincterotomy and balloon revision were performed-these were negative for stones. He still remained asymptomatic at the end of the follow-up.

When comparing the evolution of the groups according to the recurrence of pancreatitis, the patients who underwent an ES did not present the complication, but such complications appeared in 4/48 (8.3\%) of those without sphincterotomy and none of those who had cholecystectomy. This difference, although very close to the limit, was statistically significant (Table 5).

\section{Discussion}

At the time of this study, ERCP was considered the best method for the diagnosis and treatment of choledocholithiasis in our clinic. The use of a non-invasive examination such as MRC was not available in routine clinical practice; endosonography and/or intraductal ultrasound (IDUS) were unavailable. Intraoperative cholangiography was used very rarely. In our hospital, ERCP was still the main study method for bile duct stones.

All of our cases corresponded to mild pancreatitis, and ERCP was performed non-urgently. ERCP itself has risks as evidenced by $1.8 \%$ of post-ERCP acute pancreatitis that occurred in patients in this study. However, the complication rate tends to be low in a tertiary setting with a large volume of patients and experienced endoscopists as shown previously in our clinic [34].

Today, ERCP is considered a therapeutic procedure. It has been replaced by non-invasive or less invasive studies for the detection of stones in the bile duct. Currently, MRCP and EUS are used routinely in such preoperative studies.

In patients with intermediate risk of choledocholithiasis, the American Society for Gastrointestinal Endoscopy (ASGE) recommends an MRCP or EUS be 
Table 5. Recurrence according to the type of treatment.

\begin{tabular}{cccccc}
\hline & \multicolumn{2}{c}{ GROUP I } & \multicolumn{2}{c}{ GROUP II } & \\
\hline & $\mathrm{n}=53$ & $\%$ & $\mathrm{n}=48$ & $\%$ & $\mathrm{p}$ \\
\hline Recurrence & 0 & 0 & 4 & 8.3 & $0.0476^{* * *}$ \\
No recurrence & 53 & 100 & 44 & 12.5 & \\
\hline
\end{tabular}

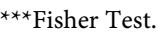

performed prior to ERCP. These have an accuracy of $85 \%$ to $95 \%$ similar to that described for ERCP [35] [36] [37] [38].

In acute biliary pancreatitis however, the MRCP does not seem to be as good as previously thought. Its sensitivity decreases as the size of the stones diminish-these are between 33\% - 71\% for stones smaller than $6 \mathrm{~mm}-$ these are the ones that are most frequently associated with acute biliary pancreatitis [39] [40] [41] [42]. Thus, some authors propose to carry out an EUS prior to ERCP even if the MRCP is negative. This would make it possible to avoid ERCP in $60 \%-73 \%$ of patients and reduce morbidity and mortality and costs associated with the procedure [43] [44] [45].

The vast majority of studies that have investigated this topic do not have a subsequent follow-up; therefore, the possibility of false negatives when performing cholecystectomy cannot be ruled out [7].

In a previous study at our centre, 90 consecutive patients who were admitted with the diagnosis of mild acute biliary pancreatitis and gallbladder in situ were prospectively studied. Of the total, 36 presented choledocholithiasis (40.4\%), 17 had multiple stones (47.2\%), and 24 (66.7\%) had stones that measured less than $5 \mathrm{~mm}$ in diameter [34].

In this study, the absence of stones in the bile duct was considered only when considering the ERCP image (less invasive examinations were not readily available at our clinic).

ERCP currently plays a less important role than it did before non-invasive studies were available. However, MRCP and EUS are not always accessible and are sometimes contraindicated; thus, the experience of medical teams with the procedures in each workplace and the extensive waiting lists can play a considerable role in the final decision for its use either as a diagnostic or as an aid in addition to fulfilling its therapeutic role.

Most data in the literature generally suggest very good positive predictive values (PPV) and negative (NPV) for the MRCP, respectively. However, Srinivasa et al. [46] selectively evaluated the use of this diagnostic modality in patients admitted to the hospital with gallstone pancreatitis and found a significant number of false negative results in patients who had ERCP follow-up. In their work, they questioned the ability of MRCP to detect choledocholithiasis in the context of gallstone pancreatitis because its sensitivity is reduced to 62\% [46].

Aydelotte [47] found that a negative MRCP was assumed to be truly negative, but that this was not the case at his institution. A negative test was not actually 
much better than chance (54\% NPV).

Acute biliary pancreatitis tends to recur especially if the cause that triggers it persists [48] [49]. For cases that present a mild form, the ideal is to perform a cholecystectomy during the initial hospitalization [34] [50].

This may not always be possible, however, either due to clinical factors, patient preference, or limited resources of the surgical wards [51] [52] [53]; thus, many patients are discharged and referred for rehospitalization for cholecystectomy. This can take a long time or is simply not done. UK studies have reported that up to one third of patients do not receive any treatment within a year after discharge from hospital [14] [51]. Indeed, our figures show that at the end of a long follow-up (average 105 months), 17.8\% of the patients had not yet been treated surgically (Table 2).

The prevalence of stones in the common bile duct can change over time. $\mathrm{Pa}$ tients without stones on admission may have them at the time of surgery because the migration of small stones and biliary sludge from the gallbladder to the common bile duct can occur just before the operation or even during surgical manipulation of the gallbladder [19] [20] [21] [22] [23].

The role of ERCP with ES as an early intervention in acute biliary pancreatitis has been controversial for years. The potential benefit of early decompression of the biliopancreatic system has been compared with the risks associated with ERCP and ES [53] [54] [55] [56].

In patients with acute biliary pancreatitis, ES can be performed as an early intervention to remove retained stones in the bile duct or as prophylactic treatment to prevent recurrent biliary events [7]. It is also useful to avoid recurrence in patients with cholelithiasis. It is not suitable for surgery [27] or in those in whom the cholecystectomy is not performed during the initial hospitalization. The risk of recurrent acute biliary pancreatitis is significant even if there are no stones in the bile duct; thus, some sites recommend performing an ES [53] [54] [55] [56].

Our suggest that ES allows the waiting period between the acute attack and cholecystectomy to be prolonged without increased the risk of recurrence and protects the patient from false negative diagnoses and stone migration during surgical manipulation of the gallbladder.

Although existing guidelines recommend conservative management of mild gallstone pancreatitis without cholangitis, a fairly large percentage of patients undergo endoscopic sphincterotomy as reported in large national studies from the United Kingdom and the United States [14] [15] [51] [57] [58].

However, it is clear that the number of cholecystectomized patients early after mild acute biliary pancreatitis should increase if there was greater efficiency in the health systems with a consequent decrease in complications derived from lithiasis and the need for an ES.

In a previous study from our Centre [34], data on ERCP and eventual endoscopic management in patients with mild acute biliary pancreatitis with gallbladder in situ were prospectively analysed. Here, a choledocholithiasis rate of $40.4 \%$ was 
found. In these patients, there were no doubts regarding the indication of an ES. The sphincter of Oddi was resected to prevent a new biliary obstruction and the possibility of recurrence of acute biliary pancreatitis in the remaining $60 \%$ and according to the work protocol at the time although no stones were found. We concluded that ERCP was a safe and effective method in patients with mild acute biliary pancreatitis and gallbladder in situ. In addition, this process allowed for laparoscopic cholecystectomy to be performed during the same hospitalization in the vast majority of patients. It constituted an alternative to gallbladder removal in patients with high surgical risk.

Here, all diagnostic or therapeutic procedures were performed by highly experienced endoscopists. Of the total number of patients who underwent ERCP with or without ES $(\mathrm{n}=110)$, only two patients (one from each group $(1.8 \%)$ ) presented acute pancreatitis as the only complication. This was mild in the patient subjected to ES and severe in the patient whose sphincter was not sectioned. Both were discharged in good condition and then uneventfully underwent a cholecystectomy.

After patients recovered from the first episode of mild acute biliary pancreatitis. Most clinical guidelines recommend performing a cholecystectomy to prevent recurrence of pancreatitis or other complications associated with the presence of stones such as symptomatic choledocholithiasis, acute cholecystitis, obstructive jaundice, and cholangitis [28] [43]. After cholecystectomy, the risk of recurrence of acute biliary pancreatitis is similar to that of the general population [17]. Others describe recurrence rates of $13 \%$ to $17 \%$ [40] [41]. Such relapses have been attributed to bile duct lithiasis [14] [15].

van Greenen et al. [55] searched Pub Med for observational studies and clinical (comparative) trials published in English on the topic of recurrent acute biliary pancreatitis and other complications of gallstones after the initial attack. This study concluded that cholecystectomy combined with ES was the most effective treatment to reduce the incidence of recurrent attacks.

Another author suggested that patients admitted for pancreatitis should be cholecystectomized as soon as possible or be prioritized onto a waiting list. Failing this, an alternative to surgery could be endoscopic retrograde cholangiopancreatography with sphincterotomy in selected cases [56]. Non-randomized studies evaluating the effect of cholecystectomy and additional ES in patients with pancreatitis show contradictory results [21]. However, a 2006 publication [27] recommended submitting patients to a cholecystectomy plus ERCP to prevent recurrence in patients with acute biliary pancreatitis.

On the other hand, a more recent large-scale study used data from more than 5000 patients and showed that cholecystectomy and ES offer the best long-term outcome for preventing recurrent biliary pancreatitis [29]. This work emphasized that prospective randomized clinical trials are needed to compare the long-term results of ES plus cholecystectomy with cholecystectomy alone [7] [59]. To the best of our knowledge, this report is the first to meet these conditions and confirm with long-term results the data found by other non-randomized 
studies [55] [56].

The aim of our study was to prospectively and randomly compare the long-term results of acute biliary pancreatitis treatment in patients without bile duct stones treated by cholecystectomy and ES versus simple cholecystectomy in the prevention of acute biliary pancreatitis recurrence and other biliary events.

With or without gallbladder in situ, the 53 patients in Group I (100\%) evolved without biliopancreatic complications, but only $42 / 48$ (87.5\%) of those in Group II did so $(\mathrm{p}=0.0096)$. In the latter, $6(12.5 \%)$ were complicated, and 5 had no cholecystectomy.

When comparing the evolution of the groups according to the recurrence of pancreatitis, the patients who underwent an ES did not have recurrence, but it appeared in $4 / 48(8.3 \%)$ of those without sphincterotomy. This difference was close to the limit, but reached a statistically significant difference $(p=0.0476)$ (Table 5).

Our study is the first prospective randomized report one in the literature with long-term follow-up. This confirms, what was found by other non-randomized studies with short follow-up [53] [54] [55] [56] [59], that risk of recurrence is significant in patients with mild acute biliary pancreatitis, without bile duct stones, and in whom cholecystectomy is not performed; thus, an ES is recommended.

Finally, some groups have suggested that performing ES during initial admission can reduce the risk of recurrent pancreatitis, but not reduce the risk of other biliary complications [13] [30]. The results of our study support this last statement. Indeed, the patients who underwent an ES did not develop this type of morbidity when comparing the evolution of the groups according to the presentation of biliary complications; however, this appeared in $8.3 \%$ of those without sphincterotomy. This difference was not statistically significant (Table 4).

\section{Conflicts of Interest}

The authors declare no conflicts of interest regarding the publication of this paper.

\section{References}

[1] Acosta, J.M. and Ledesma, C.L. (1974) Gallstone Migration as a Cause of Acute Pancreatitis. The New England Journal of Medicine, 290, 484-487. https://doi.org/10.1056/NEJM197402282900904

[2] Sugiyama, M. and Atomi, Y. (2004) Risk Factors for Acute Biliary Pancreatitis. Gastrointestinal Endoscopy, 60, 210-212. https://doi.org/10.1016/S0016-5107(04)01552-4

[3] Frey, C.F. (1081) Gallstone Pancreatitis. Surgical Clinics of North America, 61, 923-938. https://doi.org/10.1016/S0039-6109(16)42489-8

[4] Kelly, T.R. and Swaney, P.E. (1987) Gallstone Pancreatitis. The Second Time around. Surgery, 92, 571-575.

[5] Gislasonn, H., Vetrhus, M., Hom, A., Hoem, D., et al. (2001) Endoscopic Sphincte- 
rotomy in Acute Gallstone Pancreatitis: A Prospective Study of the Outcome. European Journal of Surgery, 167, 204-208.

https://doi.org/10.1080/110241501750099410

[6] Kaw, M., Al-Antably, Y. and Kaw, P. (2002) Management of Gallstone Pancreatitis: Cholecystectomy or ERCP and Endoscopic Sphincterotomy. Gastrointestinal Endoscopy, 56, 61-65. https://doi.org/10.1067/mge.2002.125544

[7] da Costa, D.W., Schepers, N.J., Römkens, T.E., Boerma, D., Bruno, M.J., Bakker, O.J. and Dutch Pancreatitis Study Group (2016) Endoscopic Sphincterotomy and Cholecystectomy in Acute Biliary Pancreatitis. Surgeon, 14, 99-108. https://doi.org/10.1016/j.surge.2015.10.002

[8] Hernandez, V., Pascual, I., Almeda, P., et al. (2004) Recurrence of Acute Gallstone Pancreatitis and Relationship with Cholecystectomy or Endoscopic Sphincterotomy. American Journal of Gastroenterology, 99, 2417-2423.

[9] Munsell, M.A. and Buscaglia, J.M. (2010) Acute Pancreatitis. Journal of Hospital Medicine, 5, 241-250. https://doi.org/10.1002/jhm.574

[10] Crockett, S.D., Wani, S., Gardner, T.B., Falck-Ytter, Y. and Barkun, A.N. (2018) American Gastroenterological Association Institute Guideline on Initial Management of Acute Pancreatitis. Gastroenterology, 154, 1096-1101. https://doi.org/10.1053/j.gastro.2018.01.032

[11] Working Party of the British Society of Gastroenterology, Association of Surgeons of Great Britain and Ireland; Pancreatic Society of Great Britain and Ireland, Association of Upper GI Surgeons of Great Britain and Ireland (2005) UK Guidelines for the Management of Acute Pancreatitis. Gut, 54, iiil-9.

https://doi.org/10.1136/gut.2004.057059

[12] van Baal, M.C., Besselink, G., Bakker, O.J., et al. (2012) Timing of Cholecystectomy after Mild Biliary Pancreatitis: A Systematic Review. Annals of Surgery, 255, 860-866. https://doi.org/10.1097/SLA.0b013e3182507646

[13] Besselink, M.G., Bollen, T.L., Gooszen, H.G., Schaapherder, A.F., et al. (2011) Timing of Cholecystectomy after Mild Biliary Pancreatitis. British Journal of Surgery, 98, 1446-1454. https://doi.org/10.1002/bjs.7587

[14] Johnstone, M., Marriott, P., Royle, T.J., et al. (2014) The Impact of Timing of Cholecystectomy Following Gallstone Pancreatitis. Surgeon, 12, 134-140. https://doi.org/10.1016/j.surge.2013.07.006

[15] Hwang, S.S., Li, B.H. and Haigh, P.I. (2013) Gallstone Pancreatitis without Cholecystectomy. JAMA Surgery, 148, 867-872. https://doi.org/10.1001/jamasurg.2013.3033

[16] Moreau, J.A., Zinsmeister, A.R., Melton, L.J., et al. (1988) Gallstone Pancreatitis and the Effect of Cholecystectomy: A Population-Based Cohort Study. Mayo Clinic Proceedings, 63, 466-473. https://doi.org/10.1016/S0025-6196(12)65644-4

[17] Gloor, B., Stahel, P.F., Mller, C.A., Worni, M., Bchler, M.W. and Uhl, W. (2003) Incidence and Management of Biliary Pancreatitis in Cholecystectomized Patients: Results of a 7-Years Study. Journal of Gastrointestinal Surgery, 7, 372-377. https://doi.org/10.1016/S1091-255X(02)00418-3

[18] Trna, J., SwaroopVegel, S., Pribramska, V., Chari, S.T., Kamath, P.S., Kendrick, M.L. and Farnell, M.B. (2012) Lack of Significant Liver Enzyme Elevation and Gallstones and/or Sludge on Ultrasound on Day 1 of Acute Pancreatitis Is Associated with Recurrence after Cholecystectomy: A Population-Based Study. Surgery, 151, 199-205. https://doi.org/10.1016/j.surg.2011.07.017 
[19] Venneman, N.G., Busken, E., Besselink, M.G., Srtad, S., Go, P.M., Bosscha, K., et al. (2005) Small Gallstones Are Associated with Increased Risk of Acute Pancreatitis: Potential Benefits of Prophylactic Cholecystectomy. The American Journal of Gastroenterology, 100, 2540-2550. https://doi.org/10.1111/j.1572-0241.2005.00317.x

[20] Whitcomb, D.C. (2006) Clinical Practice Acute Pancreatitis. The New England Journal of Medicine, 354, 2142-2150. https://doi.org/10.1056/NEJMcp054958

[21] Dwerryhouse, S.J., Brown, E. and Vipond, M.N. (1998) Prospective Evaluation of Magnetic Resonance Cholangiography to Detect Common Bile Duct Stones before Laparoscopic Cholecystectomy. British Journal of Surgery, 85, 1364-1366. https://doi.org/10.1046/j.1365-2168.1998.00957.x

[22] Makary, M.A., Duncan, M.D., Harmon, J.W., et al. (2005) The Role of Magnetic Resonance Cholangiography in the Management of Patients with Gallstone Pancreatitis. Annals of Surgery, 241, 119-124. https://doi.org/10.1097/01.sla.0000149509.77666.94

[23] De Waele, E., Op de Beeck, B., De Waele, B. and Delvaux, G. (2007) Magnetic Resonance Cholangiopancreatography in the Preoperative Assessment of Patients with Biliary Pancreatitis. Pancreatology, 7, 347-351. https://doi.org/10.1159/000107269

[24] Sanjay, P., Yeeting, S., Whingham, C., Judson, H., Polignaro, F.M. and Tait, I.S. (2008) Endoscopic Scphincterotomy and Interval Cholecystectomy Are Reasonable Alternatives to Index Cholcystectomy in Severe Acute Gallstone Pancreatitis. Surgical Endoscopy, 22, 1832-1837. https://doi.org/10.1007/s00464-007-9710-1

[25] Heider, T.R., Brown, A., Grimm, I.S. and Behrns, K.E. (2006) Endoscopic Sphincterotomy Permit Interval Laparoscopic Cholecystectomy in Patients with Moderately Severe Gallstone Pancreatitis. Journal of Gastrointestinal Surgery, 10, 1-5. https://doi.org/10.1016/j.gassur.2005.10.009

[26] Siegel, J.H., Veereppan, A., Cohen, S.A. and Kasmin, F.E. (1994) Endoscopic Scphincterotomy for Biliary Pancreatitis: An Alternative to Cholecystectomy in High-Risk Patients. Gastrointestinal Endoscopy, 40, 573-575. https://doi.org/10.1016/S0016-5107(94)70255-1

[27] Hammarstrom, H., Stridbeck, H. and Ihse, I. (1998) Effect of Endoscopic Sphincterotomy and Interval Cholecystectomy on Late Outcome after Gallstone Pancreatitis. British Journal of Surgery, 85, 333-336. https://doi.org/10.1046/j.1365-2168.1998.00626.x

[28] Kimura, Y., Takada, T., Kawadara, Y., et al. (2006) JPN Guidelines for the Management of Acute Pancreatitis: Treatment of Gallstone-Induced Acute Pancreatitis. Journal of Hepato-Biliary-Pancreatic Sciences, 13, 56-60. https://doi.org/10.1007/s00534-005-1052-6

[29] Mustafa, A., Begaj, I., Deakin, M., Durkin, D., Corless, D.J., Wilson, R. and Slavin, J.P. (2014) Long-Term Effectiveness of Cholecystectomy and Endoscopic Sphincterotomy in the Management of Gallstone Pancreatitis. Surgical Endoscopy, 28, 127-133. https://doi.org/10.1007/s00464-013-3138-6

[30] Ridtitid, W., Kulpatcharapong, S., Piyachaturawat, P., Angsuwatcharakon, P., Kongkam, P. and Rerknimitr, R. (2019) The Impact of Empiric Endoscopic Biliary Sphincterotomy on Future Gallstone-Related Complications in Patients with Non-Severe Acute Biliary Pancreatitis Whose Cholecystectomy Was Deferred or Not Performed. Surgical Endoscopy, 33, 3325-3333.

https://doi.org/10.1007/s00464-018-06622-9

[31] van Geenen, E.J.M., van der Peet, D.L., Mulder, C.J.J., Cuesta, M.A. and Bruno, M.J. (2009) Recurrent Acute Biliary Pancreatitis: The Protective Role of Cholecystecto- 
my and Endoscopic Sphincterotomy. Surgical Endoscopy, 23, 950-956. https://doi.org/10.1007/s00464-009-0339-0

[32] Ranson, J.H.C. (1979) The Timing of Biliary Surgery in Acute Pancreatitis. Annals of Surgery, 189, 654-663. https://doi.org/10.1097/00000658-197905000-00016

[33] Word Medical Association Declaration of Helsinki. (2013) Ethical Principles for Medical Research Involving Human Subjects. JAMA, 310, 2191-2194. https://doi.org/10.1001/jama.2013.281053

[34] Anselmi, M. and Gemmato, A.M. (2011) Rol de la colangio pancreatografía retrógrada endoscópica en pacientes con pancreatitis aguda biliar leve y vesícula in situ. Revista Médica de Chile, 63, 42-47. https://doi.org/10.4067/S0718-40262011000100007

[35] Romagnuolo, J., Bardou, M., Rahme, E., et al. (2003) Magnetic Resonance Cholangiopancreatography: A Meta-Analysis of Test Performance in Suspected Biliary Disease. Annals of Internal Medicine, 139, 547-557. https://doi.org/10.7326/0003-4819-139-7-200310070-00006

[36] Verma, D., Kapadia, A., Eisen, G.M. and Adler, D.G. (2006) EUS vs. MRCP for Detection of Choledocholithiasis. Gastrointestinal Endoscopy, 64, 248-254.

https://doi.org/10.1016/j.gie.2005.12.038

[37] Garrow, D., Miller, S., Debajyot, S., Conway, J., Hoffman, B.J., Hwaes, R.H. and Romagnuolo, J. (2007) Endoscopic Ultrasound: A Meta-Analysis of Test Performance in Suspected Biliary Obstruction. Clinical Gastroenterology and Hepatology, 5, 616-623. https://doi.org/10.1016/j.cgh.2007.02.027

[38] Tse, F., Liu, L., Barkun, A., Armstrong, D. and Moayyedi, P. (2008) EUS: A Meta-Analysis of Test Performance in Suspected Choledocholithiasis. Gastrointestinal Endoscopy, 67, 235-244. https://doi.org/10.1016/j.gie.2007.09.047

[39] Mendler, M.H., Bouillet, P., Sautereau, D., et al. (1998) Value of MR Cholangiography in the Diagnosis of Obstructive Diseases of the Biliary Tree: A Study of 58 Cases. The American Journal of Gastroenterology, 93, 2482-2490. https://doi.org/10.1111/j.1572-0241.1998.00708.x

[40] Boraschi, P., Neri, E., Bracchini, G., Gigoni, R., Caramella, D., Perri, G., et al. (1999) Choledocholithiasis: Diagnostic Accuracy of MR Cholangiopancreatography. Three-Year Experience. Magnetic Resonance Imaging, 17, 1245-1253.

[41] Zidi, S.H., Prat, F., Le Guen, O., Rondeau, L., Fritsch, J., Choury, A.D., et al. (1999) Use of Magnetic Resonance Cholangiography in the Diagnosis of Choledocholithiasis: Prospective Comparison with a Reference Imaging Method. Gut, 44, 118-122. https://doi.org/10.1136/gut.44.1.118

[42] Sugiyama, M., Atomi, Y. and Hachiya, J. (1998) Magnetic Resonance Cholangiography Using Half-Fourier Acquisition for Diagnosing Choledocholithiasis. The American Journal of Gastroenterology, 93, 1886-1890. https://doi.org/10.1111/j.1572-0241.1998.00543.x

[43] Aly, E.A., Milne, R. and Johnson, C.D. (2002) Non-Compliance with National Guidelines in the Management of Acute Pancreatitis in the United Kingdom. Digestive Surgery, 19, 192-198. https://doi.org/10.1159/000064212

[44] Polkowski, M., Regula, J., Tilszer, A., et al. (2007) Endoscopic Ultrasound versus Endoscopic Retrograde Cholangiography for Patients with Intermediate Probability of Bile Duct Stones: A Randomized Trial Comparing Two Management Strategies. Endoscopy, 39, 296-303. https://doi.org/10.1055/s-2007-966264

[45] Vázquez-Sequeiros, E., González-Panizo, F. and Boixeda-Miquel, D. (2011) Precisión diagnóstica e impacto terapéutico de la ultrasonografía endoscópica en los pa- 
cientes con sospecha intermedia de coledocolitiasis y colangiorresonancia normal. Revista Espanola de Enfermedades Digestivas, 103, 464-471. https://doi.org/10.4321/S1130-01082011000900005

[46] Srinivasa, S., Sammour, T., McEntee, B., Davis, N. and Hill, A.G. (2010) Selective Use of Magnetic Resonance Cholangiopancreatography in Clinical Practice May Miss Choledocholithiasis in Gallstone Pancreatitis. Canadian Journal of Surgery, 53, 403-407.

[47] Aydelotte, J.D., Ali, J., Huynh, P.T., Coopwood, T.B., Uecker, J.M. and Brown, C.V. (2015) Use of Magnetic Resonance Cholagiopancreatography in Clinical Practice: Not as Good as We Once Thought. Journal of the American College of Surgeons, 221, 215-219. https://doi.org/10.1016/j.jamcollsurg.2015.01.060

[48] Gullo, L., Migliori, M., Pezzilli, R., et al. (2002) An Update on Recurrent Acute Pancreatitis: Data from Five European Countries. The American Journal of Gastroenterology, 97, 1959-1962. https://doi.org/10.1111/j.1572-0241.2002.05907.x

[49] Somogyi, L., Martin, S.P., Venkatesan, T., et al. (2001) Recurrent Acute Pancreatitis: An Algorithmic Approach to Identification and Elimination of Inciting Factors. Gastroenterology, 120, 708-717. https://doi.org/10.1053/gast.2001.22333

[50] Larson, S.D., Nealon, W.H. and Evers, B.M. (2006) Management of Gallstones Pancreatitis. Advances in Surgery, 40, 265-284.

https://doi.org/10.1016/j.yasu.2006.06.005

[51] El-Dhuwaib, Y., Deakin, M., David, G.G., Durkin, D., Corless, D.J. and Slavin, J.P. (2012) Definitive Management of Gallstone Pancreatitis in England. Annals of the Royal College of Surgeons of England, 94, 402-406. https://doi.org/10.1308/003588412X13171221591934

[52] Sandzén, B., Haappamaki, M.M., Nilsson, E., Stenlund, H.C. and Oman, M. (2009) Cholecystectomy and Sphincterotomy in Patients with Mild Acute Biliary Pancreatitis in Sweden 1988-2003: A Nationwide Register Study. BMC Gastroenterology, 9, 80. https://doi.org/10.1186/1471-230X-9-80

[53] Trust, M.D., Sheffield, K.M., Boyd, C.A., et al. (2011) Gallstone Pancreatitis in Older Patients: Are We Operating Enough? Surgery, 150, 515-525.

https://doi.org/10.1016/j.surg.2011.07.072

[54] Hwang, S.S., Li, B.H. and Haigh, P.I. (2013) Gallstone Pancreatitis without Cholecystectomy. JAMA Surgery, 148, 867-872. https://doi.org/10.1001/jamasurg.2013.3033

[55] Vandervoort, J., Tham, T.C.K., Wong, R.C.K., et al. (1996) Prospective Study of Post-ERCP Complications Following Diagnostic and Therapeutic ERCP [Abstract]. Gastrointestinal Endoscopy, 43, 401.

[56] Loperfido, S., Angelini, G., Benedetti, G., Chilovi, F., Costan, F., De Berardinis, F., et al. (1998) Major Early Complications from Diagnostic and Therapeutic ERCP: A Prospective Multicenter Study. Gastrointestinal Endoscopy, 48, 1-10. https://doi.org/10.1016/S0016-5107(98)70121-X

[57] da Costa, D.W., Bouwense, S.A., Schepers, N.J., et al. (2015) Same-Admission versus Interval Cholecystectomy for Mild Gallstone Pancreatitis (PONCHO): A Multicentre Randomised Controlled Trial. The Lancet, 386, 1261-1268. https://doi.org/10.1016/S0140-6736(15)00274-3

[58] Nguyen, G.C., Tuskey, A. and Jagannath, S.B. (2008) Racial Disparities in Chlocystectomy Rates during Hospitalization for Acute Gallstone Pancreatitis: A National Survey. The American Journal of Gastroenterology, 103, 2301-2307. https://doi.org/10.1111/j.1572-0241.2008.01949.x 
[59] Bejarano-González, N., Romaguera-Monzonís, A., Garcia-Borobia, F.J., GarcíaMonforte, N., Serra-Plà, S., Rebasa-Cladera, P., Flores-Clotet, R. and Navarro-Soto, S. (2016) Influence of Delayed Cholecystectomy after Acute Gallstone Pancreatitis on Recurrence. Consequences of Lack of Resources. Revista Espanola de Enfermedades Digestivas, 108, 117-122. https://doi.org/10.17235/reed.2016.4086/2015 